\title{
Deuterium Retention and Desorption Behavior of Co-Deposited Carbon Film Produced in Gap*)
}

\author{
Yuji NOBUTA, Kenji YOKOYAMA ${ }^{1)}$, Jun KANAZAWA, Yuji YAMAUCHI, Tomoaki HINO, \\ Satoshi SUZUKI ${ }^{1)}$, Koichiro EZATO ${ }^{1)}$, Mikio ENOEDA ${ }^{1)}$ and Masato AKIBA ${ }^{1)}$ \\ Laboratory of Plasma Physics and Engineering, Hokkaido University, Sapporo 060-8628, Japan \\ 1) Japan Atomic Energy Agency, 801-1 Mukouyama, Naka-shi, Ibaraki 311-0193, Japan
}

(Received 8 December 2011 / Accepted 3 August 2012)

\begin{abstract}
Co-deposition of deuterium with carbon in an opening on a plasma-facing surface, a so-called 'gap', was simulated by using a deuterium arc discharge with carbon electrodes. The carbon deposition distribution and deuterium retention/desorption behavior of the carbon film were investigated. The amount of deposited carbon decreased exponentially with an increase of the distance from the gap entrance and more rapidly decreased with an increase in discharge gas pressure. The deuterium concentration in the carbon film increased with discharge gas pressure. At a high discharge gas pressure of $36 \mathrm{~Pa}$, the atomic ratio of $\mathrm{D} / \mathrm{C}$ in the carbon film reached as high as 0.9. Deuterium retained in the film desorbed mainly in the forms of $\mathrm{D}_{2}, \mathrm{HD}, \mathrm{CD}_{4}$ and $\mathrm{C}_{2} \mathrm{D}_{4}$. The desorption behavior of retained deuterium depended on $\mathrm{D} / \mathrm{C}$. In a film with a high $\mathrm{D} / \mathrm{C}$ ratio, desorption of $\mathrm{D}_{2}$ started at lower temperatures. The amount of desorbed hydrocarbons $\left(\mathrm{CD}_{4}\right.$ and $\left.\mathrm{C}_{2} \mathrm{D}_{4}\right)$ increased with $\mathrm{D} / \mathrm{C}$. Carbon film with high $\mathrm{D} / \mathrm{C}$ tended to contain a polymer-like structure, which could be related to the desorption behavior of the retained deuterium.
\end{abstract}

(c) 2012 The Japan Society of Plasma Science and Nuclear Fusion Research

Keywords: tritium retention, co-deposition, carbon film, thermal desorption, gap

DOI: $10.1585 /$ pfr.7.2405134

\section{Introduction}

Evaluation of tritium retention in a vacuum vessel is an important issue for ITER and next step fusion devices from the point of view of safety and operational schedule. Carbon material, such as carbon fiber composite (CFC), is a candidate divertor target material in future fusion devices. Carbon material is easily eroded by incident fuel hydrogen and the eroded carbon particles redeposit on the walls that incorporate the fuel hydrogen. It has been found that most of the fuel hydrogen remaining in the vacuum vessel accumulates in the co-deposited carbon film [1]. On the plasma facing surface, there are many openings between the plasma-facing tiles/components and these are generally called the "gap". The sputtered carbon particles, especially neutral particles, could enter into the gap and deposit on the side surface. Thus, co-deposited carbon film is produced not only on the plasma-facing surface but also in the gaps. The co-deposition of hydrogen with carbon in the gap is a significant concern because removal of fuel hydrogen in the gap is quite difficult [2-4]. In order to evaluate the in-vessel tritium inventory, it is important to investigate fuel hydrogen retention of the co-deposited carbon film within the gap.

In fusion devices with carbon materials used as their plasma-facing material, carbon atoms and hydrocarbons

author's e-mail: y-nobuta@eng.hokudai.ac.jp

*) This article is based on the presentation at the 21st International Toki Conference (ITC21). are emitted from the surface by physical and chemical sputtering processes, respectively, part of which is ionized and/or dissociated in the plasma. For hydrogen, hydrogen atoms and ions enter the gap. Therefore, many types of carbon and hydrogen particles can enter the gap and deposit there, which is a very complicated process. Then, a seperate investigation of the deposition process of each case is needed. Furthermore, deposits of neutral particles would be more important than of ions because neutral particles can enter more deeply into the gap of magnetic confinement fusion devices.

In the present study, the co-deposition of deuterium and carbon atoms in the gap was simulated by using a deuterium arc discharge with carbon electrodes. The distribution of carbon deposits in the gap and the behavior of deuterium retention in the co-deposited carbon film were examined. The relationship between deuterium desorption behavior and the microstructure of the film is also discussed.

\section{Experiment}

A deuterium arc discharge was used for the preparation of co-deposited carbon film. Figure 1 shows a schematic diagram of a vacuum chamber used for the preparation of co-deposited carbon film. The deuterium arc discharge was conducted with a discharge current of $50 \mathrm{~A}$ and a voltage of $12-16 \mathrm{~V}$. During the arc discharge, 


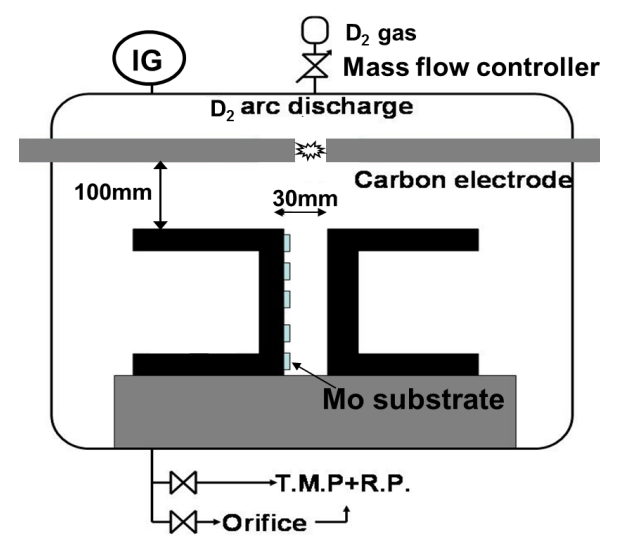

Fig. 1 Schematic diagram of vacuum chamber used for preparation of co-deposited carbon film.

a large electric current flowed through a small spot on the electrode surface and sublimation of carbon subsequently occurred. Deuterium molecules were dissociated by the arc discharge plasma, leading to the generation of deuterium atoms. The sample stage with a gap width of $30 \mathrm{~mm}$ and gap depth of $100 \mathrm{~mm}$ was placed just below the arc discharge plasma. The discharge pressure varied from 0.8 to $36 \mathrm{~Pa}$. During the discharge, both carbon and deuterium atom generated by the discharge deposited on Mo substrates placed on the sides of the gap. The deposition rate in each case was $2-4 \mathrm{~nm} / \mathrm{s}$ for the samples placed $10 \mathrm{~mm}$ away from the gap entrance, and decreased as the distance from the gap entrance increased (see Fig. 3). The substrate temperature measured using thermocouples during the discharge was below $330 \mathrm{~K}$. After the discharge, the samples were extracted from the chamber, and deuterium retention and desorption behavior of the co-deposited carbon films were investigated with thermal desorption spectroscopy (TDS). During the TDS analysis, the samples were heated at a rate of $0.5 \mathrm{~K} / \mathrm{s}$ up to $1273 \mathrm{~K}$ and then kept at $1273 \mathrm{~K}$ for $20 \mathrm{~min}$. The crystal structure of the carbon film was examined using Raman spectroscopy.

\section{Results and Discussion}

Figure 2 shows a cross section view of the codeposited carbon film prepared at $9 \mathrm{~Pa}$. The carbon film had a columnar structure which was observed to be oriented in the direction for the gap entrance. It is widely known that this inclined columnar structure is formed when the incident angle of a deposited particle is not normal to surface but has an oblique angle, and that the direction of the column is generally incline in the direction of the incoming particle [5-7]. As shown in Fig. 2, the carbon film column is inclined in the direction of the gap entrance. For this reason, the carbon atoms deposited on the Mo substrate were considered to come from the direction of the gap entrance during carbon deposition.

Figure 3 shows the distribution of the amount of de-

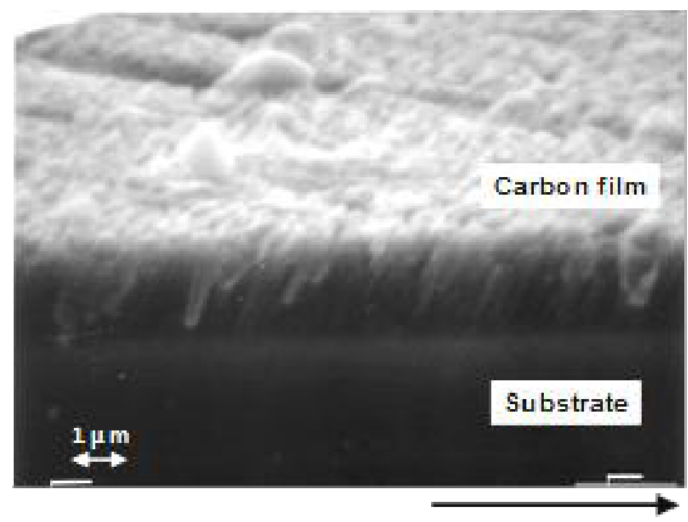

Fig. 2 Cross section view of the co-deposited carbon film prepared at $9 \mathrm{~Pa}$.

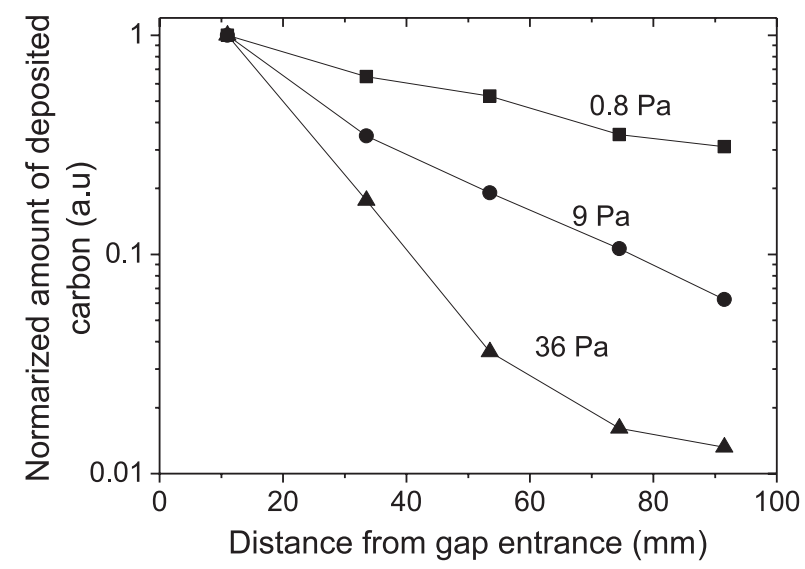

Fig. 3 Distribution of amount of deposited carbon.

posited carbon, measured by weight gain of the Mo substrate after the carbon was deposited. In this figure, the amount of deposited carbon is normalized with the deposition amount of the sample closest to the gap entrance. It was found that the carbon deposition exponentially decreased with the distance from gap entrance, and more rapidly decreased when the discharge gas pressure was high. In the case of low discharge gas pressure, some carbon atoms emitted from the carbon electrodes could directly reach deep into the gap due to a low possibility of collision with a deuterium molecule. On the other hand, in the case of high discharge gas pressure, the carbon atoms emitted from the carbon electrodes easily collide with deuterium molecules so the carbon atom hardly reach deep into the gap. This would be a possible reason for the differences in carbon deposition distribution.

Figure 4 shows the atomic ratio of retained deuterium to carbon versus the distance from the gap entrance. The $\mathrm{D} / \mathrm{C}$ ratio increased with an increase in discharge gas pressure. The arc discharge plasma was capable of producing more deuterium atoms when the discharge gas pressure is high. Also, the number of deuterium atoms produced by thermal dissociation of $\mathrm{D}_{2}$ at the carbon electrode surface 


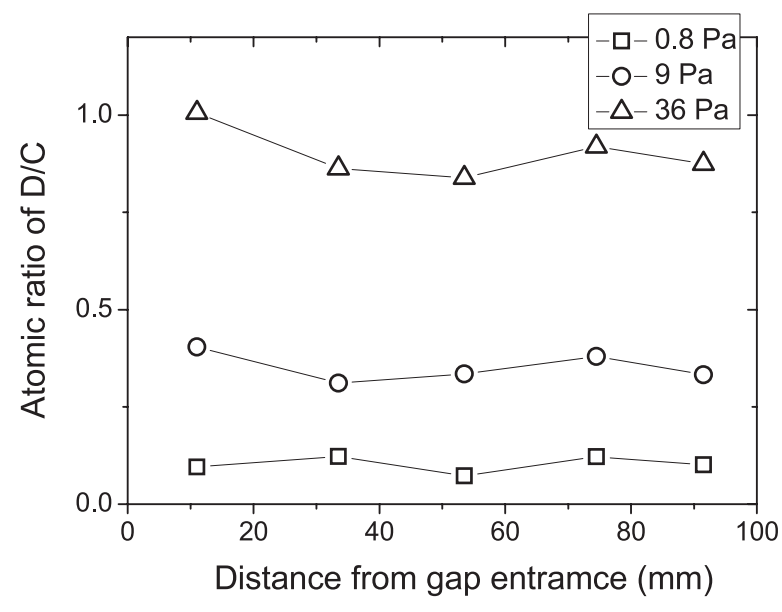

Fig. 4 Atomic ratio of retained deuterium to carbon in gap.

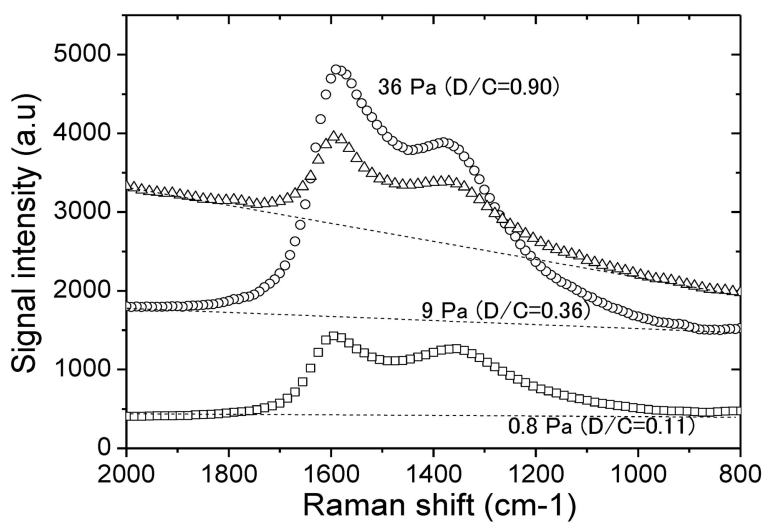

Fig. 5 Raman spectra of carbon films.

could increase with discharge gas pressure. This would be a possible reason for the increase in the $\mathrm{D} / \mathrm{C}$ ratio of the carbon film.

Figure 5 shows the Raman spectra of the carbon films. Two main peaks appeared at 1355 and $1580 \mathrm{~cm}^{-1}$, which are known as the D band and G band, respectively. These two peaks had a broad shape, indicating that the carbon films were amorphous $[8,9]$. The slope of the baseline of the spectra became steeper as the $\mathrm{D} / \mathrm{C}$ ratio increased. It is known that the slope becomes more steeper with an increase in the hydrogen concentration of the carbon film and that this is a characteristic for carbon films with a polymerlike structure [10-12]. The steep slope of the Raman spectra baseline for the carbon film with a $\mathrm{D} / \mathrm{C}$ ratio of 0.9 indicates that the carbon film is partially composed of a polymer-like structure.

Deuterium retained in the carbon film desorbed in the form of $\mathrm{D}_{2}, \mathrm{HD}, \mathrm{CD}_{4}$ and $\mathrm{C}_{2} \mathrm{D}_{4}$ in a TDS analysis. The desorption of other D-containing hydrocarbons was almost negligible. Figure 6 shows the TDS spectra of $\mathrm{D}_{2}, \mathrm{CD}_{4}$ and $\mathrm{C}_{2} \mathrm{D}_{4}$. The TDS spectra of HD was similar to that of $\mathrm{D}_{2}$. The ratio of the amount of desorbed hydrocarbon species $\left(\mathrm{CD}_{4}\right.$ and $\left.\mathrm{C}_{2} \mathrm{D}_{4}\right)$ to total deuterium retention increased with the $\mathrm{D} / \mathrm{C}$ ratio. As shown in Fig. 5, the carbon film with a (a)

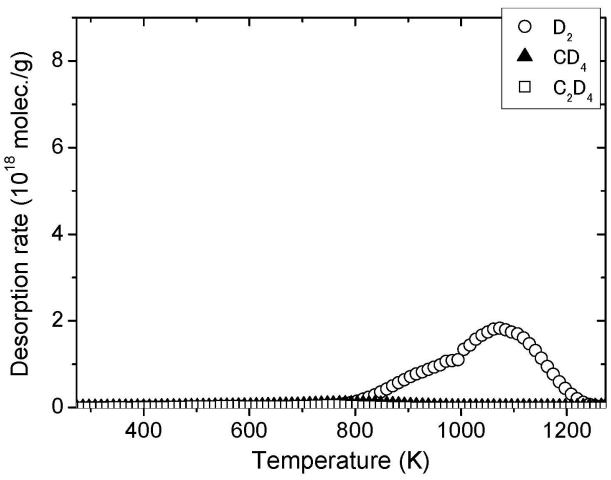

(b)

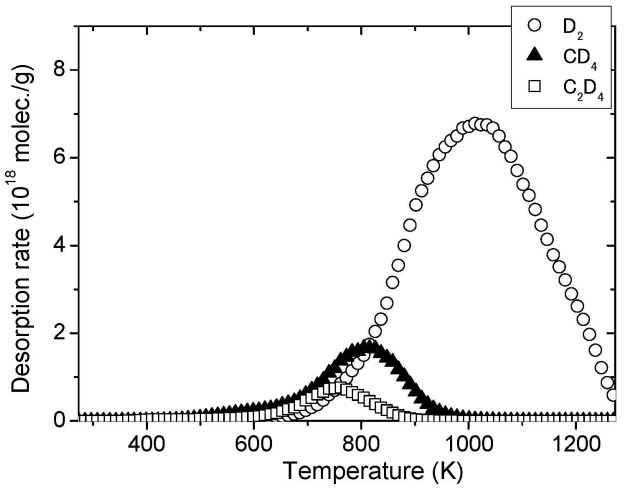

(c)

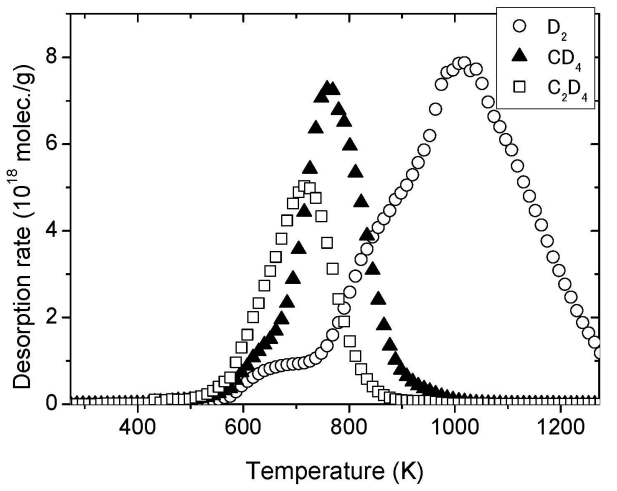

Fig. 6 TDS spectra of D2, CD4 and C2D4 for carbon film prepared at (a) $0.8 \mathrm{~Pa}(\mathrm{D} / \mathrm{C} \sim 0.11)$, (b) $9 \mathrm{~Pa}(\mathrm{D} / \mathrm{C} \sim 0.36)$ and (c) $36 \mathrm{~Pa}(\mathrm{D} / \mathrm{C} \sim 0.9)$.

high $\mathrm{D} / \mathrm{C}$ ratio contains a polymer-like structure. In the case of high $\mathrm{D} / \mathrm{C}$ ratio film, more hydrocarbon precursors (such as $-\mathrm{CD}_{3}$ and $-\mathrm{C}_{2} \mathrm{D}_{3}$ ) can be initially formed in the carbon film, and these hydrocarbon precursors would be thermally released mainly in the form of hydrocarbons in the TDS measurement. This might be a possible reason for the increase in hydrocarbon desorption. The desorption of $\mathrm{D}_{2}$ in the carbon film with a low $\mathrm{D} / \mathrm{C}$ ratio started at a temperature of around $800 \mathrm{~K}$. In the case of the carbon 
film with a high $\mathrm{D}$ concentration $(\mathrm{D} / \mathrm{C}=0.9)$, desorption of $\mathrm{D}_{2}$ started around at $580 \mathrm{~K}$, and the desorption spectra had shoulder peaks at around 630 and $810 \mathrm{~K}$, which is clearly different from the low D/C case (Fig. 6(a)). The difference of $\mathrm{D}_{2}$ desorption, again, would come from differences in microstructure.

\section{Summary}

In the present study, deuterium desorption/retention behavior and carbon deposition distribution in the gap were investigated for the co-deposited carbon film produced by a deuterium arc discharge using carbon electrodes. Carbon deposition decreased exponentially with an increase of the distance from gap and more rapidly decreased with discharge gas pressure. This result suggests that in fusion devices the neutral gas pressure in the gap strongly influences the distribution of carbon deposition. The deuterium concentration in the carbon film increased with the discharge gas pressure. In the case of $36 \mathrm{~Pa}$, the $\mathrm{D} / \mathrm{C}$ ratio reached as high as 0.9 , which is higher than that of a graphite material after energetic hydrogen irradiation [13]. The desorption behavior of retained deuterium depended on the deuterium concentration. In a film with a high deuterium concentra- tion, the desorption of $\mathrm{D}_{2}$ started at a lower temperature and the desorption of hydrocarbons $\left(\mathrm{CD}_{4}\right.$ and $\left.\mathrm{C}_{2} \mathrm{D}_{4}\right)$ increased. The carbon film with high a $\mathrm{D} / \mathrm{C}$ tended to contain a polymer-like structure, which could affect the desorption behavior of the retained deuterium.

These results indicate that the discharge gas pressure significantly affects the distribution of carbon deposition and desorption/retention behavior of hydrogen in the codeposited carbon film produced in the gap.

[1] G. Federici et al., Nucl. Fusion 41, 1967 (2001).

[2] I. Tanarro et al., J. Nucl Mater. 390-391, 696 (2009).

[3] C. Hopf et al., J. Nucl. Mater. 363-365, 882 (2007).

[4] T.S. Selinger et al., J. Nucl. Mater. 390-391, 602 (2009).

[5] M. Nieuwenhuizen et al., Philips Tech. Rev. 27, 87 (1966).

[6] R. Messier et al., J. Vac. Sci. Technol. A18, 1538 (2000).

[7] R.N. Tait et al., Thin Solid Films 226, 196 (1993).

[8] K. Niwase et al., J. Nucl. Mater. 191-194, 335 (1992).

[9] M. Yoshida et al., J. Nucl. Mater. 386-388, 841 (2009).

[10] C. Casiraghi et al., Diamond Relat. Mater. 4, 1098 (2005).

[11] J. Likonen et al., J. Nucl. Mater. 337, 486 (2008).

[12] B. Marchon et al., IEEE Trans. Magn. 33, 3148 (1997).

[13] V. Kh. Alimov, Phys. Scr. T108, 46 (2004). 